\title{
LA DESCRIPCIÓN DE LAS PARTES DE LA ORACIÓN EN LAS ARTES DEL CACHIQUEL: MÉTODOS Y FUENTES
}

\author{
THE DESCRIPTION OF PARTS OF THE SENTENCE \\ IN THE ARTS OF CACHIQUEL: METHODS AND SOURCES
}

\author{
María de los Ángeles García Aranda \\ Universidad Complutense de Madrid \\ magaranda@filol.ucm.es
}

RESUMEN: Este artículo tiene como propósito mostrar y analizar las descripciones de las partes de la oración (nombre, pronombre y partes indeclinables de la oración) que se realizaron sobre el cachiquel en la época colonial (1523-1821) gracias a los textos de Domingo Basseta, Francisco de la Parra, Benito de Villacañas, Francisco Ximénez, Carlos José Rosales, José Ildefonso Flores y Esteban Torresano, así como presentar y examinar el entorno en que fueron compuestas y las fuentes que las inspiraron, con el fin de contribuir a la lingüística misionera, sus circunstancias, sus métodos y sus tradiciones.

Palabras clave: artes; cachiquel; partes de la oración; época colonial; Guatemala.

Aвstract: This article presents and analyzes the descriptions of the parts of the sentence in Cachiquel (name, pronoun and indeclinable parts of the sentence) made in colonial times (1523-1821) in texts by Domingo Basseta, Francisco de la Parra, Benito de Villacañas, Francisco Ximénez, Carlos José Rosales, José Ildefonso Flores and Esteban Torresano. It also studies the context in which they were written and the sources that inspired them. The article hopes in this way to contribute to our understanding of missionary linguistics, their circumstances, methods and traditions.

Keywords: arts; Cachiquel; parts of the sentence; colonial times;

Guatemala.

Recepción: 25 de octubre de 2016; aceptación: 4 de octubre de 2017. 
INTRODUCCIÓN*

Durante la etapa colonial, y dado que la comunicación con los indios resultaba necesaria para la evangelización, diversos misioneros enviados a Guatemala se ocuparon de la descripción del cachiquel, lengua que tuvo tal importancia en la colonización de la Nueva España que llegó a contar con una cátedra de prima en la Universidad de San Carlos de Guatemala ${ }^{1}$.

Siguiendo la senda de los franciscanos para el náhuatl (sobre todo el Arte de la lengua mexicana de Andrés de Olmos, 1547, y el Arte de la lengua mexicana y castellana de Alonso de Molina, 1571), quienes "sufrieron mucho por no tener quien les enseñara y por no tener gramáticas ni diccionarios que, al menos por escrito, pudieran ayudarles" (Hernández de León-Portilla 2010, p. 79), y teniendo presentes las Introductiones latinae de Antonio de Nebrija ${ }^{2}$, varios misioneros de otras tantas órdenes religiosas se enfrentaron a la gramatización del cachiquel, tarea nada fácil si se tiene en cuenta que se trata de una lengua aglutinante; ergativa; sin marcación del género; con ausencia de número (en la mayoría de casos) y declinaciones en los sustantivos; con relaciones posesivas diferentes; con pronombres personales proclíticos y enclíticos con diferentes funciones sintácticas y semánticas; con numerosas partículas modales, temporales y aspectuales; con un complejo sistema de derivación de palabras o con diferentes

* Este trabajo se enmarca dentro del Proyecto de Investigación "Biblioteca Virtual de la Filología Española. Fase II. Consolidación, mejora y ampliación de los datos y de la web. Estudio de los materiales contenidos" (FFI2014-5381-P).

${ }^{1}$ El cachiquel fue una de las lenguas más importantes en la Guatemala colonial: la ubicación del pueblo que la hablaba, las circunstancias de la conquista y colonización de la Nueva España, los intereses económicos de la Corona o los objetivos de la Iglesia despertaron el interés por su aprendizaje, por lo que universidades y colegios universitarios se esmeraron en disponer los títulos y grados correspondientes, de manera que "llegaron a crearse en América una cincuentena de centros de estudios superiores. Según ordenaba el monarca, nadie podía recibir órdenes sacerdotales sin haber aprobado antes, en la Universidad respectiva, un curso completo en la lengua de los indios y nadie debía postularse para un curato indígena, si no había rendido el correspondiente examen del idioma ante los profesores universitarios de esa disciplina" (SueIro Justel 2002, p. 47).

${ }^{2}$ A diferencia de lo que ocurre en otros casos (por ejemplo, en la gramática del tarasco de Maturino Gilberti, en donde Cristina Monzón, 1997, demostró la influencia del texto latino de Despauterio), las gramáticas cachiqueles se inspiraron en la tradición grecolatina por medio de Antonio de Nebrija y de otras gramáticas amerindias, fundamentalmente del náhuatl. 
partículas relacionales y direccionales o locativas que no siempre se comportan como las preposiciones romances.

Este trabajo tiene como objetivo presentar y analizar las descripciones que se hicieron de las partes de la oración ${ }^{3}$ del cachiquel en la época colonial (1523-1821), el contexto en que fueron compuestas y las fuentes que las inspiraron, con el fin de contribuir a la lingüística misionera, sus circunstancias, sus métodos y sus tradiciones, pues

hace falta estudiar y juzgar el trabajo de los "colegas coloniales" desde una perspectiva crítica y de sensibilidad histórica a la vez. No se trata ni de alabar desmesuradamente los logros (aunque sorprenda la excelencia de algunos) ni de ridiculizar con la facilidad de un saber posterior las fallas y los errores, sino analizando ambas hay que describir cuidadosamente y sin prejuicios (ni positivos ni negativos) esta empresa fascinante de manejar una situación científica en ese entonces única para la solución de la cual no tenían experiencia (Zimmermann 1997, pp. 16-17).

\section{LA CODIFICACIÓN GRAMATICAL DEL CACHIQUEL: MODELOS TEÓRICOS}

La composición de artes y vocabularios en el Nuevo Mundo no puede separarse del proceso de evangelización: los misioneros se vieron en la necesidad, si querían que la palabra de Dios llegara a los indios, de aprender sus lenguas y, para facilitar su aprendizaje a futuros miembros de la Congregación, de componer textos que las describieran. Pese a que a lo largo del siglo XvI se legisló -las Leyes de Burgos de 1512, de Valladolid de 1513 y la Cédula Real del 3 de julio de 1596 son muestra de ello- para imponer el uso del castellano en el Nuevo Mundo, la lentitud del procedimiento hizo desistir a la Iglesia, que cambió radicalmente de estrategia: en lugar de que los indios aprendieran el español, aconsejó a sus misioneros el aprendizaje de las lenguas indígenas; de esa manera, se aseguraba la rápida y asequible cristianización de los indios. Por ello, se impone una política lingüística que exige el conocimiento de las lenguas nativas para la evangelización ${ }^{4}$ (Ridruejo 2007, pp. 440 ss.).

${ }^{3}$ Dejo fuera de este análisis el verbo, categoría gramatical que exige un estudio individual y profundo por su gran complejidad.

${ }^{4}$ Durante el siglo XVII, diversas Cédulas Reales (1603, 1618, 1619, 1624 
Guatemala no fue, en este sentido, una excepción, y dominicos, franciscanos y jesuitas, entre otros, decidieron enfrentarse a los no pocos problemas que conllevaba la descripción de las lenguas amerindias, ya que el modelo teórico que aplicaron no fue otro que las Introductiones latinae de Antonio de Nebrija, lo que "por un lado era sin duda el mejor modelo y constituía entre los posibles modelos el mejor ofreciendo un marco de referencia heurístico para el análisis lingüístico, pero seguirlo con demasiado rigor podía perjudicar la investigación y la presentación de los datos" (Zimmermann 1997, p. 14).

El proceso de gramatización del cachiquel, de construcción de "artefactos lingüísticos", no difiere del aplicado a otras lenguas amerindias o filipinas, de modo que la mayoría de las artes compuestas en este período por misioneros -la exogramatización de la que habla Silvain Auroux- se ocupan de describir, teniendo como modelo las Introductiones latinae de Antonio de Nebrija $^{5}$, la estructura y las categorías gramaticales del cachiquel, lo que ha permitido calificarlas como gramáticas pedagógicas y aplicadas, "no principalmente científicas, lo que se profesa abiertamente en algunas" (Zimmermann 1997, p. 15).

y 1637) se propusieron "vigilar y comprobar el nivel de conocimiento de lenguas nativas que debían tener los sacerdotes encargados de las parroquias. En ocasiones se llega a sancionar económicamente a los sacerdotes que desconozcan el idioma de sus feligreses -como aparece recogido en la Real Cédula de 2 de diciembre de 1578- o, incluso, a removerlos de sus cargos" (Sueiro Justel 2002, pp. 46-47). Medina Escudero (1988, p. 171) recoge, en este sentido, el fragmento de las Actas del Capítulo Provincial del 10 de mayo de 1654 en el que se ordena y manda "con todo rigor a todos los hermanos jóvenes, lo mismo a los que ya están asignados a los pueblos de los indios que a los que hayan de ser asignados, que se consagren y pongan todo el empeño posible en aprender el idioma de los indios".

5 Cf. Alvar 1992; Auroux 1992, 1994, 1997, 1998 y 2006; Hernández de León-Portilla 1993; Koerner 2006; Ridruejo 2007; SuÁrez Roca 1992 y Zwartjes 2000. Las Introductiones latinae -o teniendo en cuenta la fecha tardía de estos textos, el Arte reformado o De institutione grammatica libri quinque (1601), versión revisada de las Introductiones que preparó Juan Luis de la Cerda y que se impuso de forma oficial para el aprendizaje del latín (cf. GIL 1997 y SÁnchez SALOR 1999 y 2000) - fueron muy conocidas en América: en la casi totalidad de libros de embarque, registro de aduanas y libros de transacciones se mencionan ejemplares de las Introductiones, de manera que "podría decirse que en casi todas las partidas de libros figuran sus obras [las de Antonio de Nebrija], destacándose de esta manera como el autor español más difundido en la Colonia" (Torre Revello 1991, p. 207). 
Por ello, las descripciones del cachiquel atienden, pese a las diferencias con el latín ${ }^{6}$, a ocho partes de la oración -nombre, pronombre, verbo, participio y partes indeclinables o preposición, adverbio, interjección y conjunción ${ }^{7}$, "la composición de esta lengua es muy diversa de la Latina, pero no obstante procuraré conformarme en todo lo posible al Arte de latinidad que compuso Antonio de Nebrija, siguiendo el orden de las partes de la oración" (Flores 1753, p. 13) - y armonizan conceptos como juntar / poner juntos / añadir partículas, aditos, anteponer, mudar sílabas, simplicidad del verbo, inhesión de los accidentes, hacer por circunloquios o sinalef $a^{8}$, que responden a la naturaleza aglutinante y no flexiva de la lengua amerindia -en la que diferentes lexemas y afijos, con significados diferentes, se unen para formar nuevos signos lingüísticos en los que son muy frecuentes los cambios morfofonológicos-, con el metalenguaje descriptivo de la gramática grecolatina, pues, como señala José Luis Suárez Roca para las gramáticas del náhuatl:

${ }^{6}$ Los gramáticos-misioneros del cachiquel reconocen, al igual que otros misioneros, las diferencias con el latín en la descripción gramatical, pero, pese a ello, dedican en sus gramáticas capítulos o epígrafes a todas las categorías gramaticales grecolatinas, distanciándose así de autores como Olmos, quien la divide en tres: nombres, verbos y partes indeclinables (ZwARTJES 2003, p. 315).

7 Las artes del cachiquel se ocupan mayoritariamente de las partes de la oración, esto es, de la etymología, y no así de la prosodia o de la constructio o sintaxis. Algunas de ellas, en cambio, comienzan con un capítulo dedicado a la ortographía, que no es sino una explicación de los sonidos del cachiquel inexistentes en latín y en romance.

8 Ascensión Hernández de León-Portilla (2009, p. 176) ha afirmado, tras sus investigaciones sobre las gramáticas del náhuatl, otra lengua aglutinante, que quienes "llegaron de lenguas indoeuropeas... quizá percibieron que para el estudio de la materia gramatical era muy difícil separar totalmente el contenido morfológico del sintáctico, como en la tradición clásica y por ello, al entrar en la descripción de las categorías gramaticales, tocan necesariamente las posibilidades de componerse unas palabras con otras, tal y como aparecen en la frase. Este hecho es totalmente comprensible si pensamos que en lenguas como el náhuatl rara vez se presentan el nombre, el pronombre y el verbo en estado absoluto; casi siempre aparecen compuestos con pronombres y partículas". De la misma manera, Otто ZwARTJEs (2003, p. 310) afirma que "cuando [los misioneros] intentaron encontrar equivalentes para las tradicionales ocho partes de la oración en la lengua náhuatl, se vieron confrontados con la realidad de la lengua azteca. El náhuatl es una lengua polisintética que, además, posee prefijos y sufijos. La estructura tan ajena de la palabra-oración no tenía nada que ver con lo que los misioneros sabían de lenguas y las descripciones de éstas". 
la aplicación del modelo descriptivo de la gramática latina permitía, por un lado, exponer de forma más breve y cómoda el sistema de la lengua indígena, dado que los lectores a quienes se destinaban estas gramáticas estaban supuestamente familiarizados con el discurso gramatical latino. Por otro lado, poder regular un idioma vulgar conforme a los parámetros de aquél significaba para el pensamiento humanista renacentista elevarlo a la condición de lengua de cultura, dignificarlo, y en último término desterrar la idea de que sus hablantes fuesen unos 'bárbaros'. No poco conseguían los frailes al mostrar que la lengua india tenía así 'orden y concierto', poseía un 'artificio' equiparable al de la latina (2000, pp. 76-77).

\section{LAS ARTES DEL GACHIQUEL}

El corpus de gramáticas compuestas en la época colonial sobre el cachiquel está formado por ${ }^{9}$ :

1. El Vocabulario en lengua castellana cachiquel chi y quiché chi; en la primera división se pone la lengua castellana, en la $2^{a}$ la cachiquel y en la $3^{a}$ quiché ("acabelo en este pueblo de Sacualpa a 16 de noviembre de 1695”, hoja 194) ${ }^{10}$ de Domingo Basseta, que a partir del folio $218 \mathrm{r}$ y hasta el $221 \mathrm{v}$ compendia varios capítulos con contenido gramatical.

2. El Arte, pronunciación y ortographía de la lengua en el mismo idioma cachiquel (segunda mitad del siglo XVI) de Francisco de la Parra, redactado a partir de un escrito anterior de otro franciscano, Pedro de Betanzos, y que antecede al Ramillete manual para los yndios sobre la doctrina christiana ${ }^{11}$ de Francisco Maldonado $^{12}$ (copia conservada de 1748), obra que se centra en la explicación del significado y la práctica del culto.

${ }^{9}$ Para una descripción de las obras lingüísticas del cachiquel en la época colonial, véanse GARcía ARANDA 2013 y 2016.

${ }^{10}$ Utilizo el ejemplar que adquirió la Biblioteca Nacional de España en 2011 con signatura MSS 23234.

${ }^{11}$ Hay un ejemplar del Ramillete manual de Maldonado con el Arte, pronunciación y ortographía de la lengua en el mismo idioma cakchequel en la Biblioteca de la American Philosophical Society de Filadelfia (ms. 497.4/M29).

12 David Vela (1956, pp. 380-381) afirma que "era nativo de Guatemala, teólogo y conocedor de los idiomas quiché, cachiquel y zutuhil; dejó al morir 14 volúmenes manuscritos en la biblioteca del Convento de San Francisco de Guatemala; otras fueron traducidas al castellano para uso de misioneros y párrocos". Entre estas obras se encuentran Explication Fidei en la lengua cakchiquel, Ha nima Vuh theologia indorum ru binaam, Impedimentos del matrimonio para los indios y orden que se debe guardar en denunciarlos y acudir por dispensación 
3. El Arte de la lengua cachiquel (principios del siglo XVII) de Benito de Villacañas (con una edición facsímil y estudio de María Ángeles García Aranda en 2013) ${ }^{13}$.

4. El Arte de las tres lenguas cachiquel, quiché y tzutuhil (¿1720?, manuscrito conservado en la Newberry Library, transcrito por Rosa Helena Chinchilla en 1993) de Francisco Ximénez ${ }^{14}$.

5. La Gramática del idioma cakchiquel (1748, editada por Daniel Sánchez García en $1920^{15}$ ) de Carlos José Rosales.

6. El Arte de la lengva metropolitana del reyno cakchiquel o gvatemalico, con un paralelo de las lenguas metropolitanas de los reynos kiché, cakchiquel y tzutuhil, que hoy integran el reyno de Guatemala, primera gramática impresa del cachiquel (Guatemala, imprenta de Sebastián de Arévalo, 1753) ${ }^{16}$ de José Ildefonso Flores,

para los contraídos, Sermones super evangelia que in sanctorum festivitatus leguntur, Manual para los indios sobre la doctrina cristiana...

${ }^{13}$ Utilizo el ejemplar manuscrito copiado por K.H. Berendt que se encuentra en la Biblioteca de la Universidad de Pensilvania con signatura Ms. Coll. 700.

${ }^{14}$ Dominico nacido en Écija (1666) que aprendió quiché, cachiquel y zutuhil durante los años que pasó en Guatemala. Es autor de la Historia de la Provincia de San Vicente de Chiapa y Guatemala de la Orden de los predicadores (1722), del Párroco perfecto, de un Tesoro de las lenguas cackchiquel, quiché y tzutuhil, de un Vocabulario de la lengua cakchiquely de una transcripción y traducción al español del Popol Vuh, que lleva por nombre Empiezan las historias del origen de los indios de esta Provincia de Guatemala y que recoge leyendas y mitos (mezcladas con la historia) del pueblo quiché.

${ }^{15}$ Daniel Sánchez García modificó considerablemente el contenido original del texto: insertó "una Doctrina Cristiana que encontramos en un manuscrito antiguo" y el "Paralelo de las lenguas quiché, cachiquel y zutuhil" de FLORES (1753) y cambió "su antigua ortografía y a veces alguna que otra expresión”. En la Biblioteca Virtual de la Filología Española, http:/ /www.bvfe.es, se puede consultar el ejemplar de la Agencia Española de Cooperación Internacional para el Desarrollo (AECID), Biblioteca Hispánica, Madrid, 3GR-7571.

16 He utilizado el ejemplar que se encuentra en la Biblioteca Nacional de España, signatura R/101714 y R/101715 (se pueden consultar en red varios ejemplares en la Biblioteca Virtual de la Filología Española). Pese a ser la primera gramática impresa del cachiquel colonial, los únicos trabajos sobre el Arte de Flores hasta la fecha son el de Carmelo Sáenz de Santa María, "Dos grandes filólogos hispanoamericanos: Fray Francisco Ximénez, O.P., y Fray Ildefonso Joseph Flores, O.F.M." (1941), en el que se describe someramente, en apenas seis páginas, la obra de Flores, principalmente la parte dedicada a sonidos y grafías (el resto está dedicado a la evangelización de Guatemala, a la enseñanza de lenguas, a la variedad dialectal indígena, a la gramática comparada o a las conclusiones), y el estudio introductorio a la edición facsímil moderna del Arte de Flores hecho por el historiador JuAN José BALLESTA (2002), quien analiza con detalle cuestiones como el contexto histórico de la Gramática, el análisis codicológico del Arte, los datos biográficos de Flores 
lector de Philosophía, predicador y cura doctrinero por el Real patronato del pueblo de Santa María de Jesús y "professor of Cakchiquel in the University of Guatemala".

7. El Arte de lengua cakchiquel (1754) de Esteban Torresano, que no es sino "enumeración y corrección del Arte de la lengua metropolitana del reyno cakchiquel o guatemalteco por el P. Ildefonso Joseph Flores, Guatemala, 1753"17.

En la Tabla 1, se muestran los principales rasgos de estos textos y de sus autores: fecha probable de composición (entre 1695 y 1754); orden religiosa a la que pertenecían los misioneros (que ayudará en el establecimiento de las relaciones filogenéticas); inclusión de paratextos (con interesante información sobre las motivaciones que condujeron a la elaboración de las obras); gramática o contenido gramatical (algunas de ellas contienen, fundamentalmente, gramáticas y otras apenas unos folios con indicaciones gramaticales muy parcas); otras lenguas (fue frecuente la descripción de varias lenguas amerindias en la misma obra); léxico (a veces estas gramáticas se prepararon junto a vocabularios y diccionarios muy extensos) y doctrina cristiana (una característica de los textos lingüísticos misioneros fue su aparición junto a otros pasajes de contenido religioso):

\section{TABLA 1}

\begin{tabular}{|c|c|c|c|c|c|c|c|}
\hline & Basseta & De la Parra & Villacañas & Хіте́nez & Rosales & Flores & Torresano \\
\hline Año & 1695 & $\begin{array}{l}2^{a} \text { mitad } \\
\text { del s. XVI }\end{array}$ & Ppios. XVII & ¿ $1720 ?$ & 1748 & 1753 & 1754 \\
\hline $\begin{array}{l}\text { Orden } \\
\text { religiosa }\end{array}$ & Dominico & Franciscano & Dominico & Dominico & Franciscano & Franciscano & Franciscano \\
\hline Paratextos & $\mathrm{X}$ & $\mathrm{X}$ & $\mathrm{X}$ & $\sqrt{ }$ & $\mathrm{X}$ & $\sqrt{ }$ & $\mathrm{X}$ \\
\hline Gramática & $\mathrm{X}$ & $\mathrm{X}$ & $\sqrt{ }$ & $\sqrt{ }$ & $\sqrt{ }$ & $\sqrt{ }$ & $\sqrt{ }$ \\
\hline $\begin{array}{l}\text { Contenido } \\
\text { gramatical }\end{array}$ & $\sqrt{ }$ & $\sqrt{ }$ & - & - & - & - & - \\
\hline $\begin{array}{l}\text { Otras len- } \\
\text { guas }\end{array}$ & $\mathrm{X}$ & $\mathrm{X}$ & $\mathrm{X}$ & $\begin{array}{l}\text { quiché, } \\
\text { zutuhil }\end{array}$ & $\begin{array}{l}\text { quiché, } \\
\text { zutuhil }\end{array}$ & $\begin{array}{l}\text { quiché, } \\
\text { zutuhil }\end{array}$ & $\begin{array}{l}\text { quiché, } \\
\text { zutuhil }\end{array}$ \\
\hline Léxico & $\sqrt{ }$ & $\mathrm{X}$ & $\sqrt{ }$ & $\mathrm{X}$ & $\mathrm{X}$ & $\mathrm{X}$ & $\mathrm{X}$ \\
\hline $\begin{array}{l}\text { Doctrina } \\
\text { cristiana }\end{array}$ & $\sqrt{ }$ & $\sqrt{ }$ & $\mathrm{X}$ & $\mathrm{X}$ & $\sqrt{ }$ & $\mathrm{X}$ & $\sqrt{ }$ \\
\hline
\end{tabular}

y la descripción del contenido de la dedicatoria, la censura, la aprobación, las licencias y las erratas.

17 Utilizo el ejemplar que se encuentra en la Biblioteca de la Universidad de Pensilvania, signatura Coll. 700, ítem 54, y la versión fotografiada de la Newberry Library de Chicago, signatura Ayer ms. 1509. 
De estos textos sólo son propiamente artes gramaticales los de Villacañas, Ximénez, Rosales, Flores y Torresano; el contenido gramatical de Basseta se reduce a una enumeración en latín y en español de algunas preposiciones, adverbios, interjecciones y conjunciones (véase infra) y el Arte de Francisco de la Parra se limita a una descripción y enumeración de los caracteres inventados por Betanzos para representar otros tantos fonemas del cachiquel inexistentes en español, y que fueron utilizados con posterioridad en la mayoría de textos lingüísticos sobre el cachiquel. Tampoco resulta interesante para nuestro propósito el Arte de Torresano, pues se limita a reproducir, con alguna simplificación del contenido y alguna alteración del orden de aparición de los capítulos, el Arte de Flores. El resto, con mayor o menor fortuna, con más o menos detenimiento, trataron de describir la gramática del cachiquel aplicando el modelo teórico de las Introductiones latinae de Antonio de Nebrija, "el instrumento que facilitó la codificación gramatical de las lenguas americanas y su aprendizaje" (Hernández de León-Portilla 1993, p. 207).

\section{EL NOMBRE: SUSTANTIVO Y ADJETIVO ${ }^{18}$}

Las gramáticas del cachiquel describen su complejo sistema nominal, muy diferente del latino o del español, a partir de

18 En la reproducción de los textos gramaticales del cachiquel respeto las grafías utilizadas por los misioneros e incluyo los caracteres inventados por Francisco de la Parra para representar los sonidos guturales del cachiquel, inexistentes en español, a saber, cuatrillo (4); cuatrillo con coma (4,); tresillo $(\varepsilon)$; $t z$; la hache aspirada (4h). En la actualidad, estos símbolos se corresponden con: 4 = k' ("la $k$ seguida de apóstrofo representa un sonido mucho más profundo y cerrado que el de la $k$, emitiéndose con un cerrar y abrir de las cuerdas vocales, con ayuda de la uvular"); 4 , = tz' ("La $t z$ juntas seguidas de apóstrofo representan el sonido glotalizado de la $t z$ "); $\varepsilon=$ q' ("la $q$ seguida de apóstrofo representa el mismo sonido de la c' [ $c$ glotalizada: representa un sonido que se reproduce en la misma posición de la $c$ castellana, a diferencia de un cerrar y abrir de las cuerdas vocales durante la emisión del sonido, con lo cual se produce un casquido en la velar] y se usa antes de $e$ y de $i$, con una $u$ de por medio para seguir la regla del castellano que, y qui"); $\mathrm{tz}=\mathrm{tz}$ ("la $t z$ juntas representan un sonido alveolar, para cuya reproducción se disponen los elementos vocales para producir sy se pronuncia $t$, como en quetzal"); $4 \mathrm{~h}$ = ch' ("la $c h$ seguida de apóstrofo representa un sonido que se produce en la misma posición de la $c h$ castellana, a diferencia de que esta $c h$ 'es glotalizada"). Cf. Alfabeto para los cuatro idiomas indigenas mayoritarios de Guatemala, INI, 1950, p. 18, y Los idiomas mayas de Guatemala, Oxlajuuj... 1993, p. 123. 
varios aspectos: la posesión del sustantivo, su pluralización y su composición ${ }^{19}$. Los marcadores de posesión o morfemas del juego A o ergativo (que sirven también para indicar el sujeto de los verbos transitivos) dan lugar a sustantivos invariables, esto es, que no sufren cambios al ser poseídos; sustantivos que cambian la vocal al ser poseídos; sustantivos sustractivos que pierden el sufijo que tienen en la forma no poseída; sustantivos agregativos, es decir, aquellos que agregan un sufijo al ser poseídos, sustantivos siempre poseídos o que no se pueden usar sin el morfema que indica posesión; sustantivos nunca poseídos que siempre se usan, por tanto, en forma absoluta y sustantivos supletivos o que modifican completamente su raíz al ser poseídos.

Sólo algunos de ellos se pluralizan con un sufijo y, según su composición, pueden ser simples, compuestos por dos raíces o complejos formados por dos palabras. Además, el productivo pero complicado sistema de derivación de esta lengua ofrece raíces y afijos con numerosos valores y funciones (raíces adjetivales, verbales, sustantivales, afectivas, medidas, direccionales...; afijos intransitivizadores, agentivizadores de transitivos, sustantivizadores agentivos, locativos o instrumentales, transitivizadores causativos, pasivizadores...) que deben ser tomados en cuenta en cualquier aproximación a la lengua amerindia.

Los misioneros, con el modelo latino como guía, tratan de dar cuenta de las peculiaridades de los sustantivos y adjetivos cachiqueles, lo que supone una gran dificultad, pues no se declinan; la mayoría carece de flexión, se indica la posesión de forma muy dispar (por medio de los afijos antepuestos de posesión) y su composición y derivación resultan determinantes en algunos casos.

Por todo ello, tanto Olmos como Molina prescinden de la caracterización del nombre como declinable y se concentran en subrayar "la existencia de un plural de cosas animadas", el tratamiento de los nombres primitivos y derivativos y el funcionamiento de los nombres "al componerse con pronombres y partículas con las que se une en primera instancia para formar la frase nominal" (Hernández de León-Portilla 2009, pp. 179180, y 2011).

19 Véanse los textos gramaticales de la Academia de Lenguas Mayas de Guatemala 2006; Chacach Cutzal 1999; Comunidad Lingüística Kaqchikel de la Academia de Lenguas Mayas de Guatemala 2003; EnOe Son Chonay et al. 2014; García Matzar y Rodríguez Guaján 2001; Herbruger y Díaz Barrios 1956; Rodríguez Guaján 1994; Tema Bautista et al. 2004 y Yool Gómez 2001. 
De la misma manera, la mayoría de las gramáticas coloniales del cachiquel se limitan a ofrecer el plural de los sustantivos animados, la diferencia entre simples y compuestos, la lista de morfemas de posesión que permite declinar el sustantivo con prefijos y no con sufijos como en latín ${ }^{20}$, los cambios morfofonológicos que originan y algunos afijos denominales y deadjetivales.

\section{El sustantivo}

La gramática de Villacañas apenas dedica espacio a la descripción del nombre, pues "todos los nombres en esta lengua son indeclinables" ${ }^{21}$ (Villacañas 2013 [principios del s. XVII], p. 1), razón por la que sólo se ocupa, y muy brevemente, del número de "los nombres que significan algún accidente de fortuna o natural" (id.) a los que se les añade $A$ o I para formarlo, si bien las reglas para saber cuál es el sufijo en cada caso las enseñará el uso $^{22}$. El resto de sustantivos sólo puede pluralizarse con otros nombres o pronombres cuantificadores (dos, tres, quatro, todos...). En cambio, las gramáticas de Ximénez, Rosales y Flores, pese a reconocer que

el nombre en esta lengua no tiene ninguna declinación de casos sino solamente de números, por ser varias y diferentes sus

${ }^{20}$ Otto Zwartjes (1998, p. 118) muestra las dificultades de los misioneros con la descripción de las palabras y los morfemas, libres y ligados, avant la lettre, "ya que no pudieron basarse [a diferencia de las gramáticas de las lenguas semíticas] en una terminología o modelo precolumbiana. Esto explica la inexistencia de una nomenclatura, metalenguaje gramatical o terminología indígenas, codificada por los misioneros".

${ }^{21}$ La definición de Molina en 1571 fue: "nombre se dice de aquel que significa alguna cosa spiritual o corporal y en esta lengua ningún nombre se varía ni declina por casos así como en la latina [f. 6v.]" (Hernández de LEón-PoRTilla 2009, p. 178).

${ }^{22}$ No es raro encontrar entre los misioneros que van al Nuevo Mundo defensas del aprendizaje de las lenguas a través del uso, como recoge ANTONio Quilis (1999, p. 119) al hablar del método empleado por José de Acosta: "Para adquirir esta o cualquier lengua, hay que aprenderla con estudio cuidadoso y, después, practicarla. Se pueden aprender frases o escritos de memoria para luego repetirlos y, sobre todo, conversar con los indios, para que «oyendo y hablando se haga familiar el idioma»; después hay que decidirse a predicar, sin miedo y con audacia, pensando que hay que «exponerse a errar para dejar de errar alguna vez»". 
terminaciones; y por esta causa no tienen los nombres en estas lenguas géneros masculinos, femeninos, neutro, común de dos, ni común de tres en cuanto a la terminación de las vocales, sino en cuanto a la significación (Rosales 1920 [1748], p. 4),

o que "en este Idioma, no ay variación de casos, por distintas terminaciones, ni por éstas se conoce en qué caso está el nombre como en la Latina" (Flores 1753, p. 14), se detienen en describir los tipos de sustantivos, la formación de plural de todos los nombres y la declinación de los nombres.

Ximénez presenta un catálogo de los sustantivos y cómo éstos forman el plural a partir de sus significados: los que designan cosas inanimadas carecen de plural (aunque pueden ir cuantificados), los que designan cosas animadas "que significan accidente, de naturaleza o fortuna o acaecimiento", los "nombres participiales que significan oficios o virtudes o vicios", "los nombres denominativos que significan dos linajes, parcialidades o varios" y "los nombres propios de los indios que sacaban de los días en que nacían y de los animales y otras cosas" lo forman añadiendo $A$ o $I$; los "nombres participiales que acaban en $M$ y en $N$ " añaden $A$; "los nombres participiales acabados en $I$ que corresponden a los participios de presente" añaden $A$; "los nombres de las partes del cuerpo humano" añaden $A H$ o $I H$ (Ximénez 1993, pp. 8-10).

Rosales, primero, y Flores después, siguiéndolo, repiten el contenido de las gramáticas anteriores, esto es, que la formación del plural en cachiquel afecta sólo a los sustantivos animados, pues los inanimados carecen de plural y únicamente pueden pluralizarse si se les incorpora "algunos additos que significan pluralidad o multitud; v.g. muchos palos 4ia che, dos casas cay hay" (Flores 1753, p. 18); pero añaden, para facilitar el aprendizaje, listas de sustantivos animados en singular y en plural (nombres que forman el plural en A, nombres que hacen el plural en Iy nombres que carecen de plural y se usan siempre como absolutos), así como la formación del plural de otros sustantivos que no se ajustan a este esquema (algunos nombres de oficios, parentescos, abstractos como la mano, el paño de narices o la barriga y los sustantivos la manta y la comida), pues

para saber cuáles son los nombres que tienen plural o cuáles carecen de él no hay regla general ni hasta hoy se halla; antes sí las que ponen por generales otras Artes son las más de ellas falsas 
porque asientan una regla por general diciendo: los nombres acabados en tal o cual letra hacen el plural en esta o en aquella vocal, y en esto se halla por experiencia lo contrario, porque hay nombres que acaban en una misma letra y unos hacen el plural de una manera y otros de otra, con que más sirve de confusión al que estudia que de facilitarle el conocimiento que desea en esta materia (Rosales 1920 [1748], pp. 13-14).

Ambos autores dejan al uso, como Villacañas antes, y al ejercicio que hagan el resto. Los dos, y al igual que había hecho Ximénez, diferencian entre sustantivos "en cuanto a la significación" (Rosales 1920 [1748], p. 4), es decir, animados e inanimados y entre nombres simples, "los que por sí solos, sin addito, sin preposición y sin derivarse de otras partes significan las cosas, como Abatz, piedra, Che, palo, Vleutz, la tierra, Xan, adobe o ladrillo", y nombres compuestos,

los que nascen de verbos, activos, absolutos, passivos y neutros, y éstos propriamente se deben llamar verbales, aunque por ser en el significado mixtos, esto es, significan acciones de verbos, instrumentos o lugares en que se hazen las acciones de los verbos, y juntamente las terminaciones de los nombres se digan compuestos (Flores 1753, pp. 16-17).

Tanto Ximénez, como Rosales y Flores, a pesar de reconocer la inexistencia de declinaciones, advierten que el cachiquel indica las funciones sintácticas y semánticas por medio de los pronombres posesivos, que

son las declinaciones de esta lengua, por donde se varía y declinan todos los nombres, así sustantivos, adjetivos, como verbales; estos pronombres son de dos maneras: unos que sirven para declinar a todos los nombres que comienzan con consonante y los otros para los nombres que comienzan con vocal (Rosales 1920 [1748], p. 8),

y que no son sino morfemas antepuestos al nombre, y no pospuestos como en latín, de manera que "baluc es el cuñado [nominativo], Nubaluc, mi cuñado, Abaluc, tu cuñado, Rubaluc Pedro, el cuñado de Pedro [por estas anteposiciones se conoce la variedad de casos]" (Flores 1753, p. 14).

Ninguno de los autores puede despojarse de la tradición y se ven obligados a "orientarse por la estructura establecida por Antonio de Nebrija en su gramática latina” (Zimmermann 
1997, p. 11), de modo que, como señala Ascensión Hernández de León-Portilla en su edición del Arte de Molina de 2014, estos textos presentan el nombre

desde dos perspectivas: la de su naturaleza y la de su función. Su naturaleza está tratada desde la tradición clásica -descripción y clasificación del nombre-; su función, desde una perspectiva propia, desde el interior de la lengua, mostrando la capacidad de fusionarse con otros nombres o pronombres perdiendo o cambiando los morfemas terminales para formar un nuevo signo lingüístico (p. 75).

En suma, las propiedades del nombre cachiquel exigen a los misioneros la reestructuración de los modelos latinos, la introducción de nuevas formas de descripción gramatical y la conciliación, en la medida de lo posible, entre latín y cachiquel.

Villacañas, Ximénez, Rosales y, sobre todo, Flores se enfrentaron a ello con un éxito desigual: el primero, muy brevemente; Ximénez y Rosales, con mayor detenimiento, detalle y un número elevado de ejemplos; pero es Ildefonso Flores quien mejor y más claramente explica la forma y la tipología del nombre cachiquel, de manera que la exhaustividad en la ejemplificación y la profundidad que alcanzan algunas de sus explicaciones para transmitir la complejidad de la morfología nominal de la lengua amerindia y su lejanía con la española y la latina convierten el Arte, en palabras de José Antonio Coutiño, en el más "primoroso" de los compuestos hasta la fecha, "pero no sólo en el primoroso modo de compendiar se ostenta singular, sino también en lo que es más arduo y dificultoso, el dar a las doctrinas antiguas novedad, a las nuevas autoridad, a las obscuras luz y a las dudosas claridad" ("Parecer", en Flores 1753, [p. 7]).

\section{El adjetivo}

La diferente naturaleza del adjetivo cachiquel y del latino obliga también a limitar el contenido del capítulo al modo de adjetivar en cachiquel. Aquél no se distingue formalmente de las demás clases de palabras, pero sí forma una clase sintáctica, de manera que cualquier nombre o verbo puede funcionar como adjetivo, por lo que es frecuente en las gramáticas misioneras que sencillamente se explique "su procedencia y se proponga 
una definición de índole semántica, apartándose de la tradición clásica en la que el adjetivo se define por su capacidad de ser declinado" (Hernández de León-Portilla 2009, p. 180).

Villacañas, por ejemplo, enumera las partículas que sirven para formar adjetivos denominales: $a$, i, alah, elah, ilah, olah, ulah, de modo que abah es 'piedra' y bahelah 'pedregoso', che 'el palo', cheelah 'de palo', quec 'negro' y queca 'negra'; y nombres deadjetivales: $a l, e l, i l, o l$, $u l$, y así zac 'cosa blanca' y zacil 'la blancura'.

Ximénez, por su parte, describe $a$ ) la formación del plural de los adjetivos, "algunos nombres adjetivos hay que tienen plural añadiéndoles estas partículas: $t a c, a c, i c / i n$, utz, he, hetac/ eitzel' (Ximénez 1993, p. 10); b) las partículas que crean adjetivos denominales (alah, elah, olah, ulah, lah, nalah, ah, ic, a, i) y nombres deadjetivales $(a l, e l, i l, o l, u l)$ y $c$ ) los comparativos y superlativos

no los hay en propia voz como en la nuestra castellana, que se dice: grande, más grande y grandísimo, y como en la latina que se dice magnus, mayor, maximus; sino usando de este nombre i4ovinac que es participio de pretérito de el Vo, i4ov por pasar o sobrepasar y de este otro participio yala cuhinac, que también es de el Vo, yalacuh se hacen los comparativos y superlativos muy bien con ciertos additos (Chinchilla 1993, pp. 20-21).

Rosales y Flores dedican también sendos apartados a los modos de adjetivar y de sustantivar, con la lista de las partículas que hay que añadir para formar adjetivos y sustantivos abstractos $(A, Y$, alatz, ilatz, olatz, ulatz) y las reglas que es necesario seguir. Así, por ejemplo, se explica que nim es 'grande', nima vinak, 'persona grande' y nimal, 'la grandeza'; çak equivale a 'blanco', çaki xak a "oja blanca, que así llaman al incienso yerva" y çakil a 'la blancura'; pay se traduce por 'chocarrero' y paylatz achi por 'hombre chocarrero'; vtz es 'bueno' y vtzil, 'la bondad'.

Estos dos autores también se ocupan de comparativos y superlativos. El primero afirma que "en esta lengua son unos participios que significan pasar o exceder haciendo ventaja en algo... o con otros modos que tienen de ponderar" (Rosales 1920 [1748], pp. 23-24); y el segundo, en el capítulo sobre el adverbio, explica que

como este idioma no tiene propriamente terminación de voz para superlativo, se vale de adverbios, nombres o partículas para 
formar superlativos; v.g. muy grande o mucho con Maitz, Titz, $H a, X o o$, anteponiendo al nombre que se sigue la partícula Chi... Tampoco tiene este Idioma propria terminación de voz para el comparativo, y assí para formarlo toma algunos nombres adjetivos que significan passar, o exceder haziendo ventaja, excesso, mayoría, o al contrario con nombres que signifiquen pequeñez o diminución, y con ellos lebanta o baxa la significación haziendo siempre comparación (Flores 1753, pp. 174 y 280).

De nuevo, los misioneros evitan presentar el adjetivo como la clase de palabra que se declina junto al sustantivo, "así como en la Lengua Latina hay adjetivos v.g. Bonus, a, um, albus, a, um, \&. que juntos con substantivos hazen perfecto sentido, así en ésta, aunque sin concertar en género, número y caso como aquéllos" (Flores 1753, p. 30), y se centran en las peculiaridades del adjetivo cachiquel: su anteposición al sustantivo, su pluralización, su formación a partir de morfemas derivativos, partículas y aditos varios -lo que no resulta sencillo dada la cantidad de adjetivos derivados existentes en esta lengua (posicionales, descriptivos, intransitivos, transitivos o instrumentales)-, su función con los pronombres o la existencia de sustantivos abstractos de calidad, creados cuando se añade un determinado sufijo a la base adjetival.

Se trata, pues, de un intento de explicación de las funciones, valores y semántica del adjetivo cachiquel sin alusión alguna al latín que, en esta ocasión, impedía dar cuenta de las características reales de la lengua amerindia.

\section{EL PRONOMBRE}

Los pronombres ${ }^{23}$ o prefijos personales en cachiquel pueden ser de tres tipos: independientes o los que indican persona gramatical, los que constituyen el juego A o ergativo (que indican el sujeto de los verbos transitivos) y los que forman el juego $\mathrm{B}$ o absolutivo (y que indican el sujeto de los verbos intransitivos y los objetos de los verbos transitivos).

Los misioneros del cachiquel, de nuevo con la gramática latina y con las descripciones del náhuatl como referentes, tratan de

${ }^{23}$ Pese a que, en general, los misioneros hablan de pronombres, las marcas personales fueron descritas como formas dependientes, como afijos de sujeto y afijos de objeto de primera y segunda personas. Por otra parte, las gramáticas del cachiquel distinguen muy bien los verbos intransitivos, con un solo afijo (sujeto), de los verbos transitivos, con dos (uno sujeto y otro objeto). 
acomodar el sistema pronominal latino al de la lengua amerindia, por lo que definen el pronombre como "el que se pone en lugar del nombre" y diferencian entre pronombres primitivos (ego, $t u$, ille), que son independientes, y derivativos, que "son en dos maneras, unos que son possessivos y otros que no lo son" (Flores 1753 , p. 35) y que actúan como partículas con nombres y verbos.

Ya Alonso de Molina había estructurado el capítulo sobre los pronombres atendiendo a su definición como "aquel que se pone en lugar del nombre proprio de cualquier persona o cosa" (f. 21r), sus formas y funciones de pronombres primitivos o personales, derivativos o posesivos y reflexivos o recíprocos, con una exposición "detallada y precisa" que, "aunque se sirve de la gramática clásica, apela a su propia inventiva al clasificar ciertas formas pronominales para su mejor comprensión" (Hernández de León-Portilla 2009, p. 182).

La declinación de los pronombres primitivos o personales, según las gramáticas coloniales del cachiquel, se forma del siguiente modo: para el nominativo se utilizan in-yo, at-tú, $h a-$ aquél/él, oh/otz-nosotros, $y x / i x$-vosotros, $h$-aquéllos/ellos ${ }^{24}$; para el dativo, chuvichin/chuve-a mí o para mí, chavichin/chave-a ti o para ti, chirichin/chire-a aquél o para aquél, chikichin/chike-a nosotros o para nosotros, chivichin/chive-a vosotros o para vosotros, chiquichin/chique-a aquéllos o para aquéllos; para el acusativo con verbos en presente, quin-a mí, cat-a ti, ti-a aquél o a él, kotz- a nosotros, quix-a vosotros, que/e-a aquéllos; para el acusativo con verbos en pretérito, xin-a mí, xat-a ti, xotz-a nosotros, xix-a vosotros, xe-a aquéllos; para el acusativo con verbos en futuro, xquin-a mí, xcat-a ti, etc.; para el acusativo de contrariedad, chuvitz-contra mí, chacitzcontra ti...; para los acusativos recíprocos, vijj-a mí mismo, avij-a ti mismo, rij-a sí mismo, kij-a nosotros mismos, yvij-a vosotros mismos, quij-a sí mismos; para los ablativos, vumal-por mí, aumal-por ti, rumal-por aquél, kumal-por nosotros, yuumal-por vosotros, cumal-por aquéllos; y para los ablativos de concomitancia, vu4in/ vi4in-conmigo, au4in/aui4in-contigo, ru4in/ri4in-con aquél...

La presentación de los pronombres derivativos o posesivos ${ }^{25}$ es muy similar: las desinencias latinas, de nuevo, sirven para dar

${ }^{24}$ Como se ha dicho arriba, estos pronombres se utilizan para indicar el sujeto de los verbos intransitivos y el objeto de los verbos transitivos; es el denominado "juego B" en las gramáticas actuales del cachiquel.

${ }^{25}$ Estos pronombres son los que funcionan como el sujeto de los verbos transitivos, es decir, el "juego A" en las descripciones gramaticales actuales del cachiquel. 
cuenta de las funciones sintácticas y semánticas y para mostrar los pronombres (prefijos) que indican la posesión, el poseedor y la relación de proximidad o inherencia entre ellos -esencial en una lengua como el cachiquel, en que raramente aparecen personas o cosas sin indicar las relaciones que mantienen con otras personas o cosas-, ya que, como señala Rosales, "los pronombres posesivos son las declinaciones de esta lengua, por donde se varían y declinan todos los nombres, así sustantivos, adjetivos como verbales" (1920 [1748], p. 8).

En esta ocasión, además, los misioneros se ven obligados a detallar cambios morfofonológicos, pues estos pronombres varían en función de si el sustantivo empieza por vocal o por consonante, y es una vez más Ildefonso Flores quien mejor describe estas alteraciones:

quando el chi concurre con possessivo, que es o comienza con vocal, como concurren dos vocales la $I$ del $C h i$ y la vocal del possessivo, se usa de aquella figura Poética que llaman los Latinos synalopha, la que se comete quando en concurso de dos vocales la de la dicción siguiente se come, o como que quita o absorbe a la de la dicción antecedente (Flores 1753, p. 252).

Para facilitar su aprendizaje, Flores se sirve de dibujos o esquemas -sustituyendo los paradigmas de la gramática latinaque ilustran las diferencias entre los posesivos en cachiquel, español y latín (Figuras 1 y 2):

\section{FigurA 1}

Partículas o pronombres para nombres que empiezan por consonante

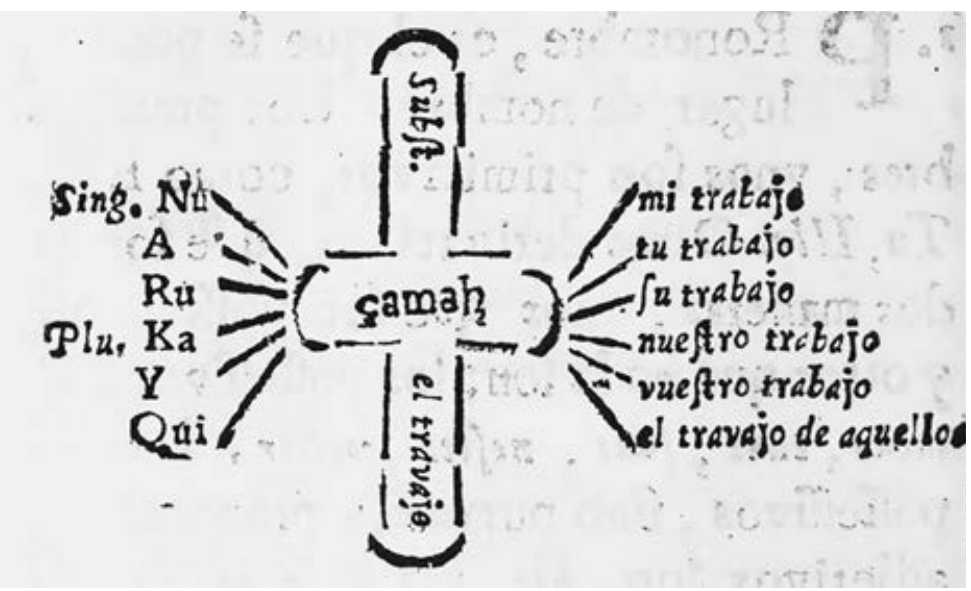


FIGURA 2

Partículas o pronombres para nombres que empiezan por vocal

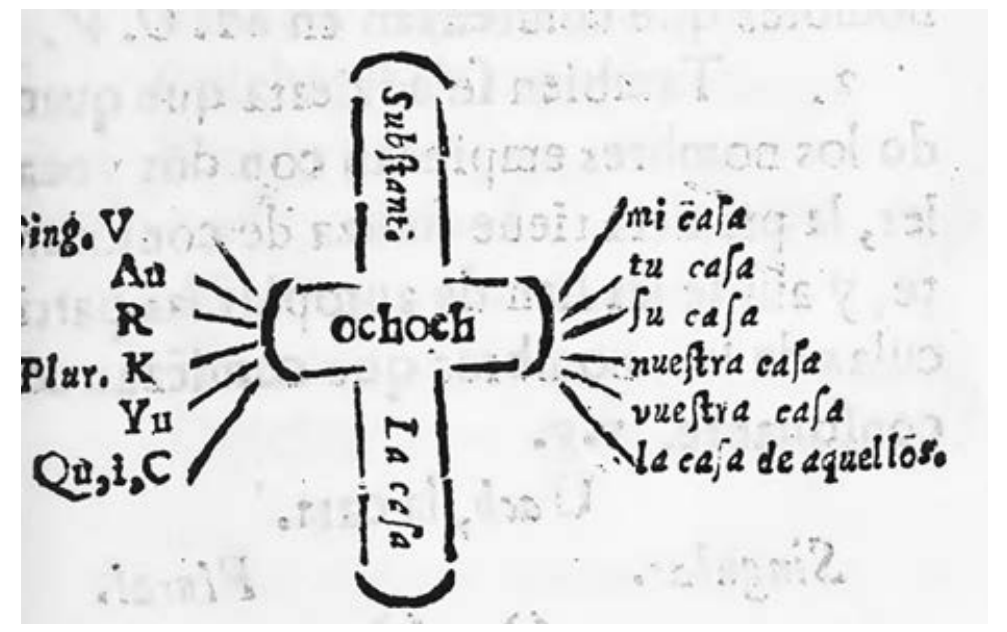

Las gramáticas suelen terminar el apartado sobre el pronombre con las partículas que en cachiquel equivalen a hic, is, iste, ille, ipse, quis vel qui, quicunque vel quivis, aliquis, unusquisque, unus/a/um, solus/a/um, totus/a/um, nullus/a/um, neutery nemo, así como con un capítulo sobre los pronombres recíprocos. En estas páginas, los misioneros explican, por ejemplo, que los demostrativos se declinan como sigue: "Re, éste o ésta, $R i$, esto o aquello, Areri o hari, aquél o aquello", "Xaui yn, yo mismo; Xaui art, tú mismo, Xaui ari, aquél mismo; Xaui otz, nosotros mismos, Xaui yx, vosotros mismos, Xaui he, aquéllos mismos", esto es, en cachiquel la declinación de estos pronombres "no es por casos sino por personas" (Flores 1753, pp. 40-41). También comentan que en lugar de unusquisque, unus-a-um, solus-a-um, nullus, neuter y nemo "se usan el numeral duplicado huhum, hun, som, manihun, xaxmanivi y hun", respectivamente (Rosales 1920 [1748], p. 11).

En el apartado sobre los pronombres recíprocos, aquellos que hacen "reciprocación o transición de una persona en otra" (Villacañas 2013 [principios del s. XVII], p. 12) o que "supponen por persona que padece, quando el mismo que haze es la que padece reciviendo en sí la acción" (Flores 1753, p. 44), Villacañas y Flores examinan la forma, el lugar de aparición (pospuestos o antepuestos al verbo según la construcción sintáctica) y la combinatoria con diferentes tiempos verbales, gerundios, participios y nombres verbales. 
En definitiva, la descripción de los pronombres en las gramáticas del cachiquel suele atender, como se acaba de mostrar, no sólo a su morfología, sino también a su sintaxis y fonemática. Los misioneros gramáticos, con las Introductiones como referente, tratan de identificar los numerosos valores, usos y cambios fónicos de los pronombres del cachiquel, inciden en aquellos que no tienen equivalentes en español o en latín, advierten de la imposibilidad en muchas ocasiones de omitir las combinatorias sintácticas de estos pronombres, tratan de diferenciar entre pronombres independientes y dependientes (o los que pueden aparecer solos y los que se unen a verbos transitivos e intransitivos) y descubren que en cachiquel en contadas ocasiones aparecen los pronombres en estado absoluto. No difieren, pues, de otros misioneros de la lengua mixteca, del zapoteco, de la totonaca, de la michuacana, de la mexicana o de las lenguas semíticas que, dado el desconocimiento en la tradición gramatical del concepto morfema, hubieron de

aislar entidades que hoy denominamos 'morfemas'. Podemos afirmar que la 'embrionaria teoría morfémica' sin duda se encuentra en las gramáticas de lenguas amerindias... Aunque en todos los ejemplos citados se trate de clases de morfemas muy distintos, es manifiesto que el rasgo común es que son inseparables careciendo de significación en posición aislada. Las definiciones de estas partes de la oración están estrechamente relacionadas y son los productos del mismo modelo metalingüístico (Zwartjes 1998, pp. 118-119).

Constituyen, pues, meritorios acercamientos a la morfología pronominal que evidencian los métodos y recursos a los que acudieron Villacañas, Ximénez, Rosales y Flores para definir una lengua que poco compartía con la latina.

\section{LAS PARTES INDECLINABLES DE LA ORACIÓN}

La mayoría de las artes gramaticales terminan con capítulos dedicados a las partes indeclinables de la oración: preposición, conjunción, adverbio, interjección y partículas, capítulos que, una vez más, definen y ejemplifican los usos de estas clases de palabras a partir de la gramática latina y muestran la dificultad que suponía para los misioneros caracterizar unidades con valores bien diferentes en cada lengua. 
Domingo Basseta, por ejemplo, presenta preposiciones, interjecciones y conjunciones en latín (extra, inter, extra, circiter, citra, apud, intra, propter, supra, a/ab, cum, et, quoniam, atque, quique...) y los equivalentes cachiqueles acompañados de algunas explicaciones y ejemplos de uso, así como una breve exposición y clasificación semántica de los adverbios de tiempo o de lugar en español y cachiquel (hoy, después, luego, ayer, antier, tres días ha, cuatro días ha, cinco días ha, seis dias ha, siete días ha, veinte dias ha, mañana, pasado mañana, de aqui a tres dias, de aqui a cuatro días, de aqui a cinco días, de aqui a veinte días, aquí, alli, en ningún lugar, arriba, bajo, debajo, allá, acá, de lado, a mi mano derecha, a mi mano izquierda...).

Villacañas, en el capítulo 11, titulado "Advertencias", da cuenta de los equivalentes de varios adverbios temporales y del significado, forma y uso de varias partículas temporales:

esta partícula vi es muy usada en la lengua y tiene muchos oficios..., quereca significa lo mismo que ergo..., esta partícula xax se junta algunas veces al participio de la oración y significa también afirmación y siempre que se pone esta partícula xax se ha de poner vi (Villacañas 2013 [principios del s. XVII], pp. 35-36).

Ximénez, Rosales y Flores, de forma más precisa y uniforme, definen, catalogan e ilustran los significados y contextos de estas unidades que, en palabras de Ximénez (1993, p. 141), son "el alma de la lengua y las que más se traquean y usan".

\section{Preposiciones}

Para la descripción de las preposiciones, y pese a las dificultades que entraña acomodarlas a la gramática latina ${ }^{26}$, utilizan a

${ }^{26}$ Ximénez, por ejemplo, reconoce que hay adverbios que "son adorno" (1993, p. 161); Rosales sólo ve parecidos entre las preposiciones de las dos lenguas en que las del cachiquel "tienen su lugar como en la latina, pues la preposición es aquella que se antepone en la oración al caso que rige y así en ésta que siempre es antepuesta", pues "en esta lengua [las preposiciones] ni rigen los casos como en la latina, ni se distinguen en la terminación, sino en cuanto a la significación solamente" (Rosales 1920 [1748], p. 76). Flores afirma, en cambio, que "en este idioma no hay preposiciones tan clara y distintamente como en el Latino, porque las más se hallan mixtas con los pronombres posesivos, y se varían por todas las personas, y sólo en la significación se conoce que son de acusativo o ablativo" (Flores 1753, pp. 248-29) 
Antonio de Nebrija: "quinta parte de la oración y aquella que se antepone a las demás partes" 27 (Flores 1743, p. 248), como ya había hecho también Alonso de Molina: "preposición se dize ser aquella que se antepone a las otras partes: las quales son muchas". El autor del Arte de la lengua mexicana y castellana

deja a un lado la idea de declinación y la define por el orden que adquiere respecto de otras palabras. Para abordar su estudio abandona la clasificación por los accidentes en especial el de caso, al que las preposiciones están ligadas en la gramática clásica y lo hace desde una perspectiva semántica y según la composición... El principal oficio de la preposición es el de ayudar a la composición y así lo destaca fray Alonso: "y es de notar que algunas preposiciones rigen solamente a los nombres y otras solamente a los pronombres y algunas indiferentemente a los nombres y a los pronombres" [f. 74v] (Hernández de León-Portilla 2009, p. 189).

Ximénez, Rosales y Flores, poco originales, agrupan las preposiciones en cachiquel bajo los epígrafes de preposiciones latinas de acusativo (ad, apud, iuxta, circa, penes, prope, erga, circiter, inter, intra, infra, sub, ante, ob, propter, per, in, procul, praeter, supra, secundum) y preposiciones de ablativo ( $a, a b, a b s, a b s q u e$, sine, cum, coram, de, e, ex, prae, pro, palam, in, tenus). Y acompañan los apartados con explicaciones minuciosas y ejemplos de uso detallados.

\section{Adverbios}

El adverbio es la "parte de la oración que junta con otras las califica aumentando o disminuyendo la significación de ellas" (Flores 1753, p. 264), definición que, procedente de las Introductiones $^{28}$, ya había recogido Alonso de Molina: "adverbio quiere decir quasi añadidura, o cosa añadida al verbo. Por quanto determina la significación del dicho verbo [f. 71r]" (Hernández de León-Portilla 2009, p. 187).

o que "en este idioma es muy escaso [el adverbio] porque para expresarlo usa muchas veces de nombre con alguna preposición" (FLores 1753, p. 264).

27 AnTONio de Nebrija la había definido como "parte de la oración que se declina y prepónese a las otras partes de la oración, o por composición o por aposición" (libro 3, p. 118).

${ }_{28}$ Para Nebrija es la "parte de la oración que no se declina y añadida al verbo hinche su significación, o la muda, o la amengua, como luego haré, no haré, poco haré" (libro 3, p. 122). 
Tanto Molina como los misioneros del cachiquel los agrupan semánticamente por su significado directo o por su finalidad; así, se describen adverbios interrogativos, demostrativos, de cantidad, de calidad, de lugar, de tiempo, de días pasados, de días venideros, de años pasados, para dar priesa o despacio, comparativos de semejanza y desemejanza, dubitativos, superlativos, comparativos y negativos.

Ximénez, Rosales y Flores, además de enumerar detalladamente los adverbios cachiqueles y de proponer sus equivalentes españoles, explican su colocación en la oración, tal y como había hecho Alonso de Molina (Hernández de León-Portilla 2009, p. 188).

A este contenido, Ildefonso Flores añade la formación de adverbios en -mente y, como es habitual en su Arte, recoge en varios esquemas su combinatoria con otras categorías gramaticales (Figuras 3 y 4 ):

vsa este Idioma de los verbales correspondientes a los adjetivos, como si en lugar de Pridenter pusiéramos Cum prudentia; assí en esta Lengua se toman los verbales y antes de ellos se pone la preposición Chi que significa Con de instrumento (Flores 1753, p. 287).

Figura 3

Adverbios negativos con verbo activo en consonante

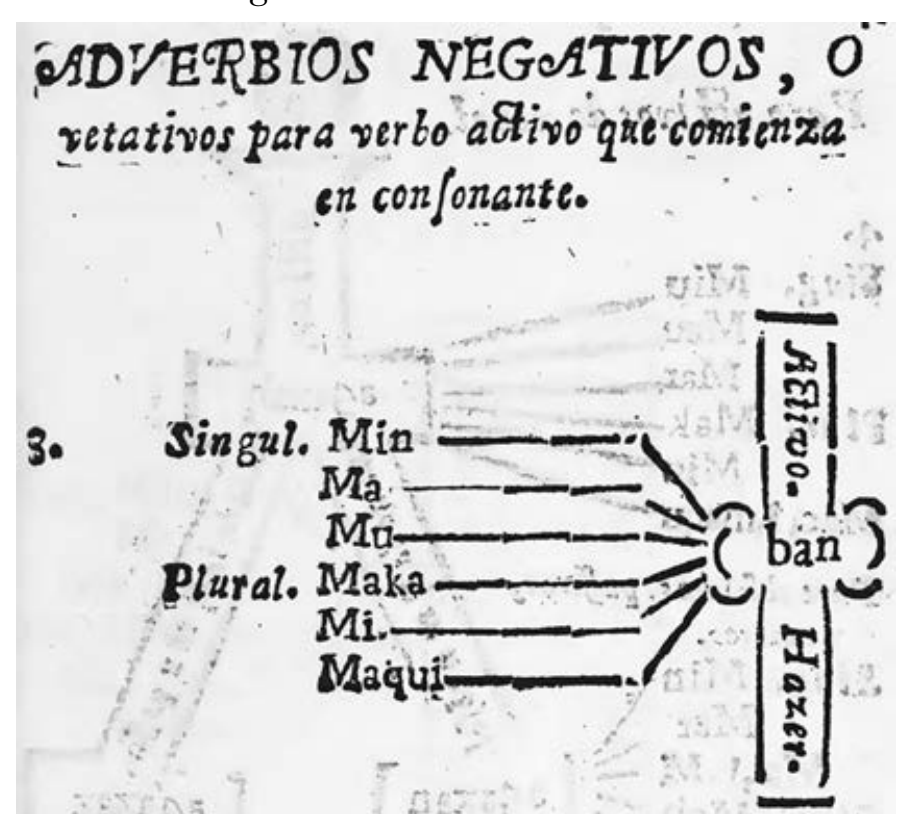

Nueva Revista de Filología Hispánica (NRFH), LXVI, 2018, núm. 2, 463-492 ISSN 0185-0121; e-ISSN 2448-6558; DOI: 10.24201/nrfh.v66i2.3424 
Figura 4

Adverbios negativos con imperativos de verbos neutros, absolutos y pasivos

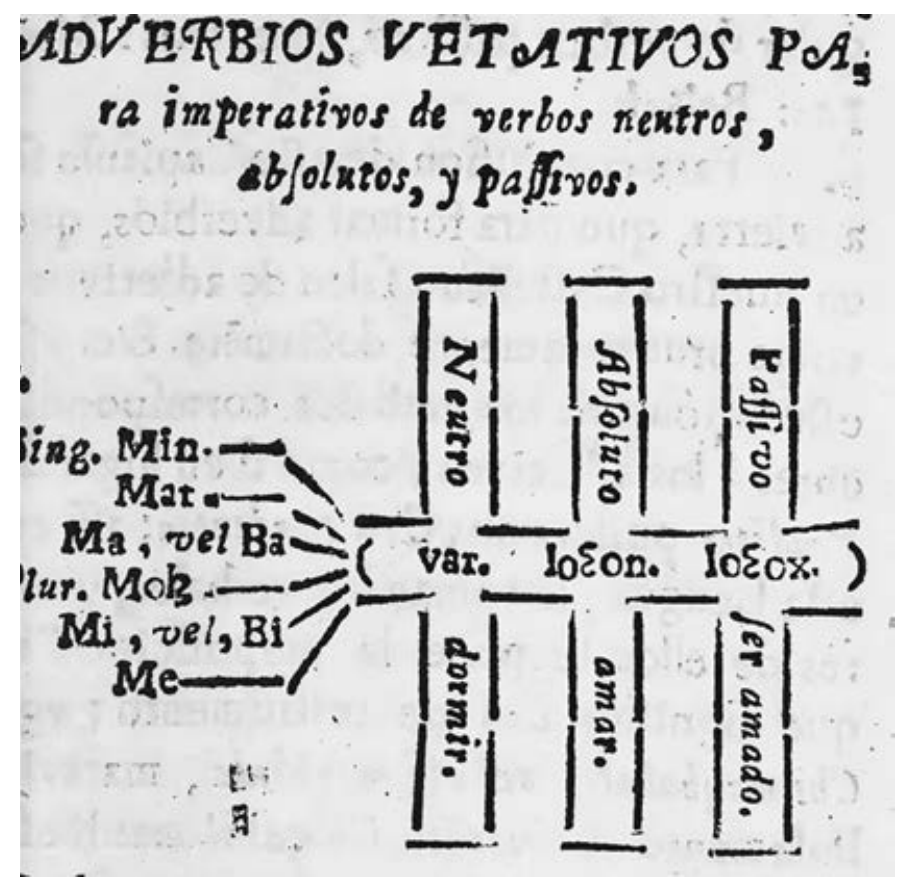

\section{Interjecciones}

Según Antonio de Nebrija, la interjección es la "parte de la oración que no se declina y significa pasión del ánima por voz incierta" (libro 3, p. 123). Alonso de Molina la define como "la que significa el afecto y deseo del alma, por alguna voz confusa. La cual no tiene propia significación como yyo, yo, o[f. 81v]" (Hernández de León-Portilla 2009, p. 191). Rosales, como las partes de la oración "demostrativas y significativas del afecto interior del alma, así de dolor y tristeza, como de alegría y placer o deseo" (1748 [1920], p. 86). Y Flores, como las que "declaran los varios afectos que hay en el ánimo" (1753, p. 288).

Unos y otros, en breves capítulos, enumeran con base exclusivamente en el accidente semántico las principales interjecciones (de dolor, de tristeza, admirativas, desiderativas, despreciativas, representativas...), sus usos y valores. Así, por ejemplo, Flores describe que atz kook es "interjección del que 
se duele, y juntamente del que se admira", como en atz kook at un Dios!, "ay mi Dios", o en atz kook vahau queretabijtz re!, "ay de mí, Señor, que tal cosa dices!” (1753, p. 289).

\section{Conjunciones}

Las Introductiones latinae caracterizan la conjunción como "parte de la oración que no se declina y traua y ordena la sentencia" (libro 3, p. 124); el Arte de la lengua mexicana y castellana, como "la que ayunta y ordena la sentencia [f. 80v]" (Hernández de LeónPortilla 2009, p. 190); y para Ximénez (1993, p. 191), Rosales (1920 [1748], p. 85) y Flores (1753, p. 290) es "la que traba y ata las demás partes".

Las conjunciones, sus equivalentes cachiqueles, su colocación antepuesta o pospuesta y sus valores oracionales se revisan también en estas gramáticas siguiendo el modelo para el latín y para el náhuatl, esto es, conjunciones copulativas, disyuntivas, adversativas, causales, condicionales... Tan sólo Ximénez cuestiona la clasificación semántica: "no se pueden poner en el método que en la lengua latina sino en otro orden que es como se sigue" (Rosales 1993 [1748], p. 191), y opta por ordenarlas a partir de su estructura silábica (conjunciones simples, compuestas).

\section{Partículas}

Rosales y Flores, al igual que Villacañas y a diferencia de Ximénez (quien les dedica un capítulo tras los verbos; véase supra), después de las partes de la oración indeclinables, incluyen varias líneas dedicadas a las partículas, "que por sí nada significan, pero juntas con otras palabras les diversifican su significación" (Flores 1753, p. 295). Los misioneros, conscientes de la importancia de estas unidades en cachiquel, las consideran como una categoría gramatical independiente y tratan de caracterizarlas a pesar de su complejidad:

Chi, esta partícula es muy trivial y difícil de explicar su adaptación, pero se atienda a que se suele poner por de principalmente después de nombre partitivo (Rosales 1920 [1748], p. 88, y Flores 1753, p. 298). 
$X a$, esta partícula sirve para afirmar (Rosales 1920 [1748], p. 88, y Flores 1753, p. 297).

$A t z$, esta partícula antepuesta al nombre significa el oficial o autor de la cosa que el nombre significa (Rosales 1920 [1748], p. 88, y Flores 1753, p. 299).

Oc, sirve para denotar exclusión (Rosales 1920 [1748], p. 89, y Flores 1753, p. 300).

$O k$, partícula de imperativo y optativo (Rosales 1920 [1748], p. 89, y Flores 1753 , p. 300$)$.

La, sirve para preguntar (Rosales 1920 [1748], p. 89, y Flores 1753, p. 301).

$X$, antepuesta a nombres, verbos o participios significa desde o después que (Rosales 1920 [1748], p. 90, y Flores 1753, p. 303).

\section{Conclusiones}

Las Artes del cachiquel compuestas en la etapa colonial deben mucho, como la mayoría de gramáticas de las lenguas amerindias, a las Introductiones latinae de Antonio de Nebrija. Sin embargo, y pese a la influencia de la lengua latina en la descripción del cachiquel y las consecuencias que de ello se derivan, estas Artes constituyen meritorios acercamientos lingüísticos a esta lengua maya.

La gramática latina de Nebrija fue la guía, pero los misioneros hubieron de realizar una importante labor de adaptación a la realidad de las lenguas indígenas. Basseta, Villacañas, Ximénez, Rosales y Flores se sirvieron de la metodología y de la nomenclatura de la gramática latina y, con frecuencia, se vieron obligados a forzar las categorías de la lengua amerindia para hacerlas concordar con las del latín ${ }^{29}$, pero también percibieron que la codificación del cachiquel exigía otros conceptos y vocablos (aditos, anteposición, posposición, circunloquios, sinalefa, añadir partículas, variar por particulas...) que dieran respuesta a las diferencias que había con el latín. No escatimaron esfuerzos, y la consulta de otras fuentes gramaticales y léxicas, el conocimiento de los textos del náhuatl o el cotejo con el español y el hebreo -en el caso de Ximénez y Flores, por ejemplo- ayudaron en sus empresas.

29 En este sentido, K. Zimmermann (1997, p. 10) afirma que las Introductiones latinae funcionaron como una "camisa de fuerza" que no siempre dejó ver las diferencias entre las lenguas. 
No todas las Artes son iguales, ni en cantidad ni en calidad: la de Domingo Basseta contiene escasa información gramatical, pero es una de las primeras descripciones del cachiquel que tenemos; la de Benito de Villacañas está dedicada, fundamentalmente, a los rasgos más característicos del nombre y del verbo; la de Francisco Ximénez, en cambio, es una gramática extensa, completa, concienzuda y prolija en ejemplos con útiles referencias al quiché y al zutuhil o con interesantes datos sobre el origen de las lenguas y la gramática comparada; el Arte de Rosales, deudora de la de Ximénez, trata de compendiar la gramática del cachiquel en un volumen que, probablemente, se compuso con la única intención de servir a los misioneros de su congregación para la comunicación con los indios, y la de Flores, inspirada y auxiliada muchas veces por las anteriores, como se ha visto en las páginas precedentes, es, con toda seguridad, la más ordenada, sistemática, cuidada y compendiosa codificación gramatical del cachiquel hecha en la época colonial.

Todas ellas, con sus logros y dificultades, son resultado del esfuerzo de unos misioneros que, a partir de un modelo claramente insuficiente, se empeñaron en describir la gramática de una lengua que poco o nada se parecía a las que ellos conocían.

\section{REFERENCIAS}

Academia de Lenguas Mayas de Guatemala 2006. Gramática normativa del idioma maya kaqchikel, Iximulew, Guatemala.

Alvar, Manuel 1992. "Nebrija y tres gramáticas de lenguas americanas (náhuatl, quechua y chibcha)", en Estudios nebrisenses. Coord. M. Alvar, Cultura Hispánica, Madrid, pp. 313-339.

Alvar EzQuerra, Manuel (dir.). Biblioteca Virtual de la Filología Española, http://www.bvfe.es.

Auroux, Silvain 1992. "Le processus de grammatisation et ses enjeux", en Histoire des idées linguistiques. T. 2: Le développement de la grammaire occidentale. Dir. S. Auroux, Mardaga, Liège, pp. 11-64.

Auroux, Sylvain 1994. La révolution technologique de la grammatisation, Mardaga, Liège.

Auroux, Sylvain 1997. "La réalité de l'hyperlangue", Languages, 31, 127, pp. 110-121.

Auroux, Sylvain et Eni Puccinelli Orlandi 1998. "Introduction" à L'hyperlangue brésilienne. Dirs. S. Auroux, E. Puccinelli et F. Mazière, Langages, Paris, núm. 130, pp. 3-7.

Auroux, Sylvain et Francine Mazière 2006. "Hyperlangues, modèles de grammatisation, réduction et autonomisation des langues”, en 
Hyperlangues et fabrique des langues. Dirs. S. Auroux et F. Mazière, Histoire Épistémologie Langage, 28, 2, pp. 7-17.

Basseta, Domingo De 1698 [2005]. Vocabulario de la lengua quiché. Ed. René Acuña, Instituto de Investigaciones Filológicas, Universidad Nacional Autónoma de México, México.

Chacach Cutzal, Martín 1999. Escribamos el kaqchiquel, Proyecto EdumayaInstituto de Lingüística y Educación, Guatemala.

Comunidad Lingüística Kaqchikel de la Academia de Lenguas Mayas de Guatemala 2003. Kojtzijon pa Kaqchikel ch'ab'äi (Conversemos en idioma kaqchikel), Iximulew, Guatemala.

Enoe Son Chona, Gloria et al. 2014. Maja'il Kaqchikel: Kaqchikel autoaprendido, Dirección Departamental de Educación, Guatemala.

Flores, Ildefonso José 1753. Arte de la lengva metropolitana del reyno cakchiquel o guatemalico, Sebastián Arévalo, Guatemala.

Flores, Ildefonso José 2002. Arte de la lengva metropolitana del reyno cakchiquel o gvatemalico. Ed. facs. con est. de J.J. Batalla Rosado, Sociedad Estatal para la Acción Cultural Exterior-Testimonio, Madrid.

García Aranda, M. Ángeles 2013. Las gramáticas y los vocabularios de las lenguas indígenas: el cakchiquel (siglos XVI y XVII), Axac, Lugo.

García Aranda, M. Ángeles 2016. "Los misioneros y el estudio de las lenguas mayas: las gramáticas del cakchiquel en la época colonial”, Hispanic Research Journal, 17, 2, pp. 89-108.

García Matzar, Pedro y José Obispo Rodríguez Guaján 2001. Gramática kaqchikel, Iximulew, Guatemala.

Gil, LuIs 1997. Panorama social del humanismo español (1500-1800), Tecnos, Madrid.

Herbruger, Alfredo y Eduardo Díaz Barrios 1956. Método para aprender a hablar, leer y escribir la lengua cakchiquel, Tipografía Nacional, Guatemala.

Hernández de León-Portilla, Ascensión 1993. "Nebrija y el inicio de la lingüística mesoamericana”, Anuario de Letras, 31, pp. 205-223.

Hernández de León-Portilla, Ascensión 2007. "Misioneros y gramáticos. Tradición clásica y modernidad mesoamericana", en Paradigmas de la palabra. Gramáticas indígenas de los siglos XVI, XVII y XVIII, Sociedad Estatal para la Acción Cultural Exterior, Madrid, pp. 37-58.

Hernández de León-Portilla, Ascensión 2009. "El Arte de la lengua mexicana y castellana de fray Alonso de Molina: morfología y composición", Estudios de Historia Novohispana, 39, pp. 167-206.

Hernández de León-Portilla, Ascensión 2010. "Paradigmas gramaticales del nuevo mundo: un acercamiento", Boletín de la Sociedad Española de Historiografía Lingüistica, 7, pp. 73-107.

Hernández de León-Portilla, Ascensión 2011. "Naturaelza y función del nombre en el Arte de la lengua Mexicana y castellana de fray Alonso de Molina”, en Lenguas en el México novohispano y decimonónico. Coord. J. Alfonso Pérez Luna, El Colegio de México, México, pp. 77-104.

Hernández de León-Portilla, Ascensión 2012. "La tradición gramatical mesoamericana. Sus orígenes y formas de expresión”, en Historiografía lingüistica: líneas actuales de investigación. Eds. E. Battaner, V. Calvo y P. Peña, Nodus Publikationen, Münster, pp. 101-115. 
Instituto Indigenista Nacional 1950. Alfabeto para los cuatro idiomas indígenas mayoritarios de Guatemala: quiché, cakchiquel, mam y kekchi, Ministerio de Educación Pública, Guatemala.

Koerner, Konrad 2006. "Gramática de la lengua castellana de Antonio de Nebrija y el estudio de las lenguas indígenas americanas: o hacia una historia de la lingüística amerindia”, en Caminos actuales de la historiografí lingüistica. Actas del V Congreso Internacional de la SEHL. Eds. R. Escavy et al., Servicio de Publicaciones, Murcia, t. 2, pp. 17-36.

Medina Escudero, Miguel Ángel 1988. "Métodos y medios de evangelización de los dominicos en América”, en Actas del I Congreso Internacional sobre los dominicos y el Nuevo Mundo. Sevilla: 21-25 de abril de 1987, Deimos, Madrid, pp. 157-207.

Molina, Alonso de 1571. Arte de la lengua mexicana y castellana, Pedro Ocharte, México.

Molina, Alonso de 2014 [1571]. Arte de la lengua mexicana y castellana. Reproducción facs. del ejemplar conservado en la colección cervantina del ITESM. Ed. crít., est. introd., translit. y notas de A. Hernández de León-Portilla, Universidad Nacional Autónoma de México-Fideicomiso Felipe Teixidor y Monserrat Alfau de Teixidor-Instituto Tecnológico y de Estudios Superiores de Monterrey, México.

Monzón García, Cristina 1997. "La influencia de Nebrija en la gramática phurhépecha de Gilberti", en Memoria del Coloquio La obra de Antonio de Nebrija y su recepción en la Nueva España, quince estudios nebrisenses (14921992). Coords. Ignacio Guzmán Betancourt y Eréndira Nansen Díaz, Instituto Nacional de Antropología e Historia, México, pp. 107-120.

Nebrija, Antonio de 1996 [ca. 1488]. Introducciones latinas contrapuesto el romance al latín. Eds. Miguel Ángel Esparz y Vicente Calvo, Nodus Publikationen, Münster.

Olmos, Andrés de 2002 [1547]. Arte de la lengua mexicana. Ed. facs. y est. de Ascensión Hernández y Miguel León-Portilla, Universidad Nacional Autónoma de México, México.

Olmos, Andrés de 2014 [1547]. Arte de la lengua mexicana. Ed. facs. y est. de Ascensión Hernández de León-Portilla, Universidad Nacional Autónoma de México, México.

Oxlajuuj keej Maya' Ajtz'iib 1993. Los idiomas mayas de Guatemala, Centro Educativo y Cultural Maya, Guatemala.

Quilis, Antonio 1999. "Las lenguas amerindias en De procuranda indorum salute de José de Acosta”, en Estudios de historiografía lingüistica hispánica ofrecidos a Hans-Josef Niederehe. Eds. María do Carmo Henríquez Salido y Miguel Ángel Esparza Torres, Universidade, Vigo, pp. 113-122.

Ridruejo, Emilio 2007. "Lingüística misionera", en Historiografía de la lingüística en el ámbito hispánico. Fundamentos epistemológicos y metodológicos. Eds. Josefa Dorta, Cristóbal Corrales y Dolores Corbella, Arco/Libros, Madrid, pp. 435-477.

Rodríguez Guaján, José Obispo 1994. Manual de redacción kaqchikel, Iximulew, Guatemala.

Rosales, Carlos Joseph 1920 [1748]. Gramática del idioma cakchiquel. Ed. Daniel Sánchez García, Tipografía San Antonio, Guatemala. 
Sáenz de Santa María, Carmelo 1941. "Dos grandes filólogos hispanoamericanos: fray Francisco Ximénez, O.P., y fray Ildefonso Joseph Flores, O.F.M.”, Revista de Indias, 2, pp. 117-132.

Sánchez SAlor, EustaQuio 1999. "La gramática de Nebrija reformada", en Actas do I Congresso Internacional: Humanismo novilatino e pedagogía. Coord. A.M. Martins Melo, Centro de Estudos Clássicos da Faculdade de Filosofia de Braga, Braga, pp. 99-129.

SÁnchez SAlor, Eustaquio 2000. "Un Nebrija reformado en Zaragoza (1610)", Calamis Renascens, 1, pp. 347-362.

SuÁrez Roca, José Luis 1992. Lingüistica misionera española, Pentalfa, Oviedo.

SuÁrez Roca, José Luis 2000. "Tradición en innovación en la descripción de la lengua náhuatl”, en Las gramáticas misioneras de tradición hispánica (siglos XVI-XVII). Ed. Otto Zwartjes, Rodopi, Amsterdam, pp. 73-95.

Sueiro Justel, JoAQuín 2002. La política lingüistica española en América y Filipinas (siglos XVI-XIX), TrisTram, Lugo.

Tema Bautista, Mario Perfecto et al. 2004. Gramática descriptiva del idioma maya kaqchikel, Comunidad Lingüística Kaqchikel de la Academia de Lenguas Mayas de Guatemala, Guatemala.

Torre Revello, José 1991 [1940]. El libro, la imprenta y el periodismo en América durante la dominación española, Universidad Nacional Autónoma de México, México.

Villacañas, Benito de 2013 [ppios. del s. XVII]. El Arte y el Vocabulario de la lengua cakchiquel de Benito de Villacañas. Est. de M. Ángeles García Aranda, Diputación Provincial de Toledo, Toledo.

XimÉnez, Fray Francisco 1993. Arte de las tres lenguas kaqchikel, fiché y tzutuhil (ms. de la Biblioteca Newberry, Chicago, Illinois). Transcr., notas y pról. de Rosa Helena Chinchilla, Academia de Geografía e Historia de Guatemala, Guatemala.

Yool Gómez, JuAn 2001. Introducción al aprendizaje oral del idioma kaqchikel, Kematzij, Guatemala.

Zimmermann, Klaus 2004. "La construcción del objeto de la Historiografía de la Lingüística misionera”, en Missionary Linguistics. Lingüistica misione$r a$. Eds. Otto Zwartjes y Even Hovdhaugen, John Benjamins, AmsterdamPhiladelphia, pp. 7-32.

Zimmermann, Klaus (ed.) 1997. La descripción de las lenguas amerindias en la época colonial, Vervuert-Iberoamericana, Frankfurt/M.-Madrid.

ZwarTJEs, Отто 1998. "La estructura de la palabra según las primeras gramáticas de lenguas mesoamericanas y la tradición greco-latina”, en Estudios de lengua y cultura amerindias II. Actas de las IV Jornadas Internacionales de Lengua y Cultura Amerindias (Valencia, $17-20$ de noviembre de 1997). Eds. D. Jorques Jiménez y J. Calvo Pérez, Universidad de Valencia-Departamento de Teoría de los Lenguajes, Valencia, pp. 99-121.

ZwARTJes, Отто 2003. "La lengua española y la teoría gramatical a través de las fuentes misioneras de la época colonial: la categoría del participio en las gramáticas del náhuatl”, en Actas del XXIII Congreso Internacional de Lingüistica y Filología Románica. Coord. Fernando Sánchez Miret, Max Niemeyer Verlag, Tübingen, t. 5, pp. 305-318.

Zwartjes, Отto (ed.) 2000. Las gramáticas misioneras de tradición hispánica (siglos XVI-XVII), Rodopi, Amsterdam. 